\title{
ANÁLISE DE MANIFESTAÇÕES PATOLÓGICAS E REPARO EM EDIFÍCIO DE CONCRETO ARMADO - ESTUDO DE CASO
}

\author{
PATHOLOGICAL MANIFESTATIONS ANALYSIS AND REINFORCED CONCRETE \\ STRUCTURE BUILDING REHABILITATION - CASE STUDY
}

\section{RESUMO}

O presente artigo trata sobre um reparo estrutural em uma edificação que apresentava manifestações patologias em Brasília, Distrito Federal. A metodologia escolhida foi o estudo de caso, onde houveram as etapas de inspeção visual, investigação, análise da estrutura existente e a reabilitação da mesma. Através das análises concluiu-se que se tratava principalmente de problemas gerados por cabonatação e variação de umidade, resultando em corrosão das armaduras. Os elementos danificados foram realcalinizados e reparados, seguindo as recomendações das bibliografias consultadas. Observa-se que apesar de terem muitos estudos sobre patologia, há uma necessidade maior de padronização e normatização brasileira da área de detecção e reabilitação, necessitando também de pesquisas de todo o comportamento ao longo da vida útil remanescente das estruturas reparadas.

Palavras-chave: Patologia. Carbonatação. Corrosão. Reabilitação. Concreto.

\section{ABSTRACT}

This paper reports on a rehabilitation of a building with pathological manifestations in Brasillia, Federal District, Brazil. The methodology chosen was a case study which was divide in visual inspection, cause investigation, structure analysis and rehabilitation. It was concluded by the researchers that the problem was generated because moisture variation and carbonated concrete surface, which the result was corroded steel bars. On the damaged reinforced concrete structures were applied electrochemical realkalisation and rehabilitated following recommendations of consulted bibliographies. Although there is a lot of studies about pathology it is notice a lack of standards e national normalization on the subject, also requiring

1 Graduada em Engenharia Civil pelo Centro Universitário do Distrito Federal (UDF). E-mail: layane.scalixto@gmail.com 2 Mestre em Estruturas e Construção Civil pela Universidade de Brasília (UNB). Docente do Centro Universitário do Distrito Federa (UDF) e perito nomeado de Engenharia no Tribunal de Justiça do Distrito Federal e Territórios (TJDFT). E-mail: hjnery@gmail.com 
researchers in the behavior of rehabilitation reinforced concrete structures through its remaining service life.

Keywords: Pathology. Carbonatation. Corrosion. Rehabilitation. Concrete.

\section{INTRODUÇÃO}

Atualmente a construção civil vem enfrentando vários problemas de estabilidade estrutural das edificações (falhas, defeitos, degradações, etc.), tais problemas são denominados manifestações patológicas. Segundo Souza e Ripper (1998) designa-se genericamente por patologia das estruturas o campo da engenharia das construções que se ocupa do estudo das origens, formas de manifestação, consequências e mecanismos de ocorrência das falhas e dos sistemas de degradação das estruturas.

Para Baver (2008), a maioria dos danos apresentados em elementos estruturais são do tipo evolutivo, ou seja, em curto prazo poderão comprometer sua estabilidade. A deterioração da estrutura poderá ser classificada conforme a sua relação em grupos, sendo eles: erros de projeto estrutural, emprego de materiais inadequados, erros de execução e agressividade do meio ambiente.

Os sintomas patológicos de maior incidência nas estruturas de concreto armado, segundo Helene (1992 apud Reis, 1998), são as fissuras, as eflorescências, as flechas excessivas, as manchas no concreto aparente, as corrosões de armaduras e os nichos de concretagem gerados pela segregação dos materiais constituintes do concreto. Tais sintomas, segundo Reis (1998), apresentam níveis de manifestações cujo quais permitem deduzir a natureza, a origem, os mecanismos e fenômenos envolvidos, além de possibilitar uma provável previsão de suas consequências.

Ainda de acordo com Reis (1998), os processos de reabilitação apresentam em sua maioria um caráter artesanal e particular, pois cada problema enfrentado possui características e soluções próprias. Portando, apesar de várias obras terem sido reabilitadas com sucesso, ainda existem vários fatores e procedimentos que necessitam ser investigados para avaliar o melhor comportamento das estruturas após as intervenções. Sendo assim, deve ser feito um diagnóstico definindo causas, consequências e as possíveis formas de solução dos problemas patológicos.

\section{METODOLOGIA}

Este trabalho se trata de um estudo de caso da reabilitação estrutural de um edifício com manifestações patológicas. A estrutura em estudo possui cerca de cinquenta anos de uso, sendo dividida em $2^{\circ}$ pavimento, $1^{\circ}$ pavimento, térreo e subsolo. Para o processo de restauração foi realizada pesquisa bibliográfica para o embasamento teórico, incluindo vistoria, anamnese, soluções e acompanhamento 
de execução. Por fim, são apresentadas as manifestações patológicas encontradas, suas causas, formas escolhidas de intervenções e análise dos processos de reparo e reforço, tendo em vista os resultados encontrados no durante a execução.

As etapas para o processo de reforço seguidas são ilustradas na Figura 1 abaixo:

Figura 1 - Processos realizados para o reparo estrutural

\begin{tabular}{|ccc}
\hline \multicolumn{4}{c}{ Inspeção Visual } & Deformações \\
\hline Fissuras & Nichos & \\
\hline Intensidade & Investigação de agentes agressores & \\
\hline Estabilidade & Localização & \\
\hline & Análise Estrutural & \\
\hline Recuperação & Segurança & \\
\hline
\end{tabular}

\section{INSPEÇÃO VISUAL E AGENTES AGRESSORES}

Na inspeção visual foram observadas armaduras expostas e em processo de degradação (Figura 2), fissuras na direção longitudinal de pilares e perda de seção devido ao desplacamento (Figura 3); problemas de execução como segregação, nicho e desaprumo (Figura 4); além de colocação escura indicando presença de microrganismos, lixiviação, eflorescências e infiltrações em estruturas expostas à água.

Figura 2 - Corrosão da armadura de vigas perimetrais

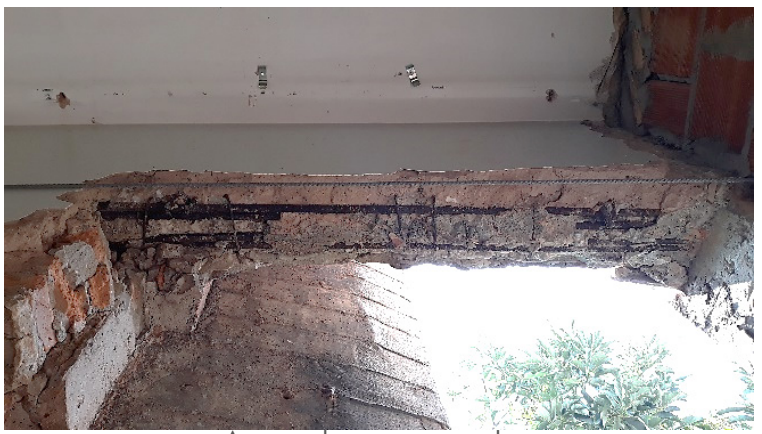

Armaduras expostas

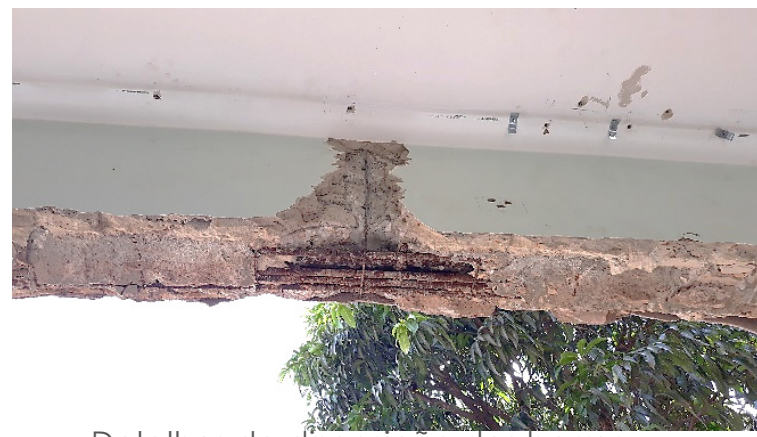

Detalhes da disposiçâo das barras 
Segundo Souza \& Ripper (1998) é indispensável o conhecimento das origens da deterioração não apenas para que possam ser realizados os reparos exigidos, mas também para garantir que após reparada, a estrutura não volte a se deteriorar.

Neste trabalho buscou-se entender os motivos das manifestações patológicas encontradas, sem classificá-las em grupos devido aos problemas de projeto, execução, materiais e outros.

Figura 3 - Corrosão da armadura dos pilares

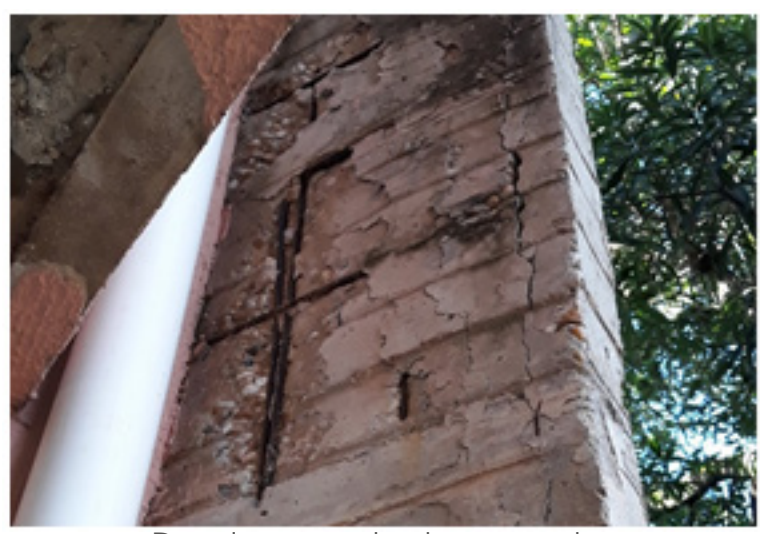

Desplacamento do concreto

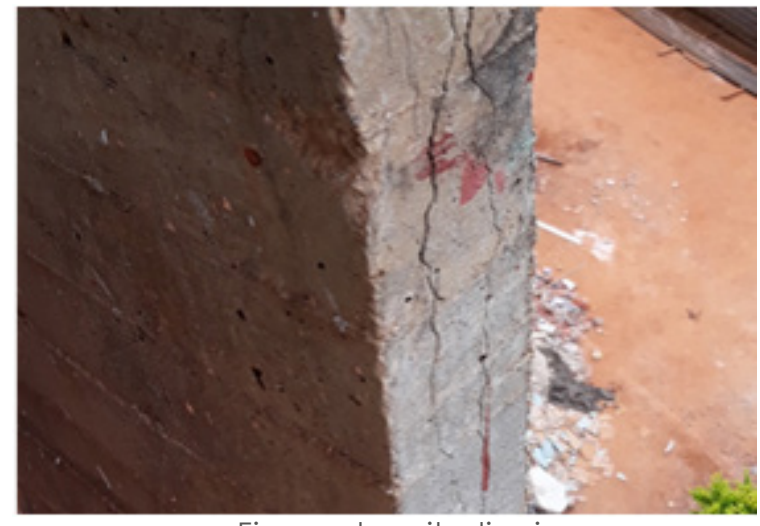

Fissuras longitudinais

Na etapa de investigação dos possíveis agentes agressores foram analisados os dados levantados na inspeção visual, onde as fissuras dos pilares-paredes se localizavam, em sua maioria, verticais, no sentido da armadura longitudinal do elemento e as vigas estavam com suas armaduras expostas. As manifestações patológicas encontradas indicam problemas de corrosão de armaduras. Segundo Helene (1993), a corrosão é a interação destrutiva de um material com o meio ambiente, como resultado de reações deletérias de natureza química ou eletroquímica, associadas ou não às ações físicas ou mecânicas de degradação. No concreto armado os efeitos degenerativos manifestam-se na forma de manchas superficiais causadas pelos produtos de corrosões, fissuras, destacamentos dos concretos de cobrimento, reduções da seção resistente das armaduras com frequente seccionamento de estribos e eventuais perdas de aderência das armaduras principais. 
Figura 4 - Falta de cobrimento e nichos de concretagem

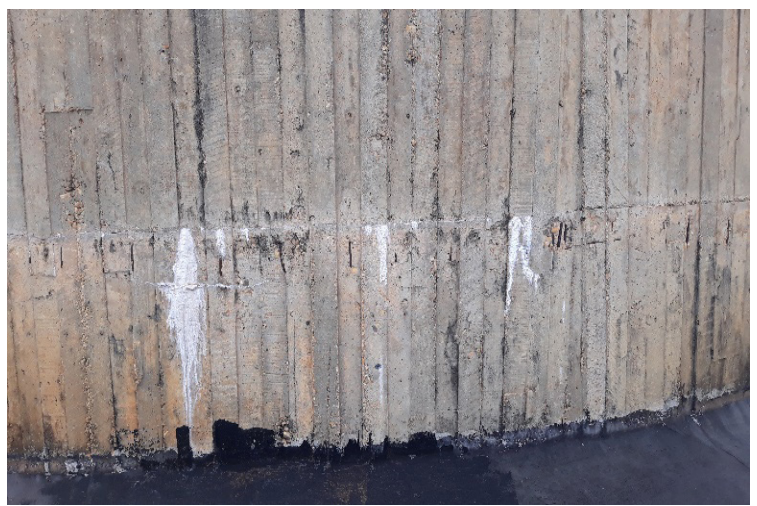

Armadura exposta e lixiviação

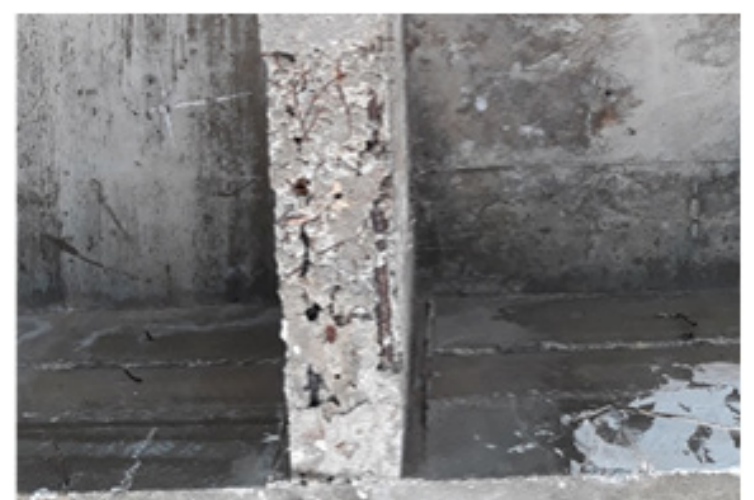

Nichos de concretagem

No concreto armado as barras de aço são dispostas de forma à possuir proteção física e química contra a corrosão. A proteção física vem da espessura do cobrimento da armadura, que impede agentes agressivos externos de terem contato com as barras, já a química é através da alcalinidade do concreto. Na inspeção visual foi possível detectar a falta de cobrimento da armadura e a acidez do concreto, cujo qual poderá ter sido o motivo da existência da corrosão, sendo este devido à uma reação eletroquímica que para Molin (1988) se dá através da presença de oxigênio, umidade, e de uma diferença de potencial entre dois pontos da barra de aço. Andrade Perdrix (1992) afirma que a corrosão pode se apresentar diversas formas, podendo ser classificadas pela extensão da área atacada. Ela denomina como as corrosões mais frequentes de: generalizada, localizada, por pites e fissurante.

Em geral, neste estudo de caso foram encontradas corrosões generalizadas, com poucas incidências de localizadas onde a mesma foi avaliada. As perdas de seção de concreto foram casos extremos oriundos do processo de corrosão, situados principalmente na parte interna dos pilares-paredes, indicando acúmulo de umidade, sendo este um agente agravante no processo de manifestações patológicas por reação eletroquímica. Foram observados cobrimentos inadequados e carbonatações do concreto em todas as peças estruturais, não sendo possível determinar se este foi um erro de concepção do projeto estrutural, pois o mesmo não foi cedido para a análise.

Nichos e variações de seções foram detectados nos pilares-paredes, indicando a inadequação do agregado graúdo, possuindo grandes dimensões para a esbeltez do elemento analisado, aumentando o risco de carbonatação.

Todas as vigas perimetrais da edificação noúltimo pavimento se encontravam com manifestações patológicas de alta intensidade com perda de cobrimento, armaduras expostas e corrosões de armaduras longitudinais inferiores. Os níveis de incidência de manifestações patológicas entre os andares foram decrescentes, ou seja, as patologias foram diminuindo, indicando que os maiores danos foram onde

\section{INTER/SCIENTIA}

REVISTA INTERSCIENTIA | V. 7 | N. 2 | P. 27-40 | JUL-DEZ/2019 
há maior projeção de chuva. Esta constatação está de acordo com as afirmações de Andrade Perdrix (1992), onde é mencionado que o teor de umidade é o fator que mais influi na velocidade de corrosão, principalmente quando há variação do mesmo, o que é típico do clima de Brasília, aonde está situada a edificação.

\section{ANÁLISE ESTRUTURAL E TIPO DE REABILITAÇÃO}

Durante a vistoria não foram observadas fissuras, flechas e outras deformações excessivas que indicassem nível elevado de comprometimento estrutural, por isto, partiu-se do pressuposto de que a estrutura existente necessitava apenas de reparo estrutural, pois ao recompor a área de aço e a seção de concreto pedida não seriam necessários reforços devido à perda parcial ou total de capacidade de carga.

São vários os tipos de processos de reabilitação estrutural, sendo escolhidos de acordo com as manifestações patológicas e o nível de degradação da estrutura de tal forma que cada reabilitação estrutural possui características próprias. De acordo com Andrade Perdrix (1992) e Ribeiro J. L. (2009), no caso de uma estrutura em processo de corrosão as funções básicas do reparo devem ser a restauração da proteção das armaduras e a reconstituição do componente de concreto, restabelecendo suas propriedades físicas, estáticas e geométricas. Tendo em vista a bibliografia consultada, o método de reparo selecionado foi a remoção por abrasão da superfície enferrujada do aço, avaliação de seção e substituição de barras quando necessário, limpeza por hidrojateamento, realcalinização e reposição da seção de concreto através do uso de argamassa polimérica monocomponente para reparos em concreto.

Primeiramente foram retirados todos os revestimentos de argamassa dos elementos estruturais que apresentavam patologias e os concretos deteriorados ao redor das armaduras (Figura 5), utilizando o martelo rompedor de 5 quilogramas. A remoção deu-se até atingir dois centímetros de distância das barras de aço, porém observou-se que devido às dimensões do seixo rolado a área removida foi ligeiramente maior do que o determinado.

Figura 5 - Remoção do concreto carbonatado

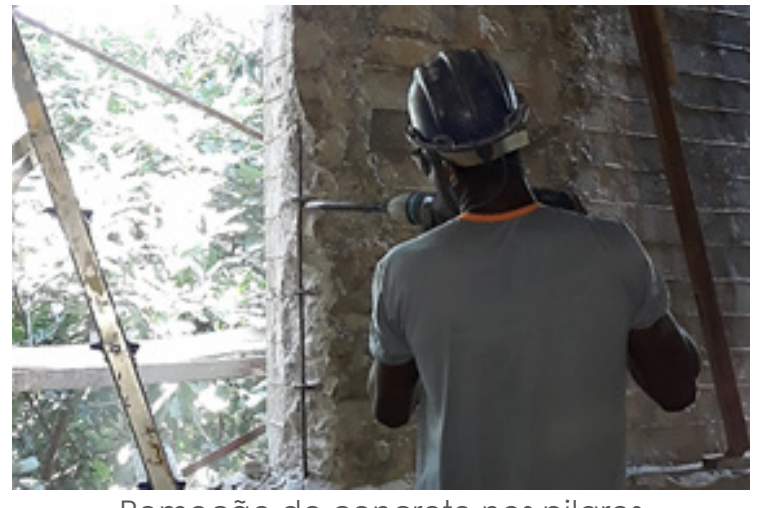

Remoção de concreto nos pilares

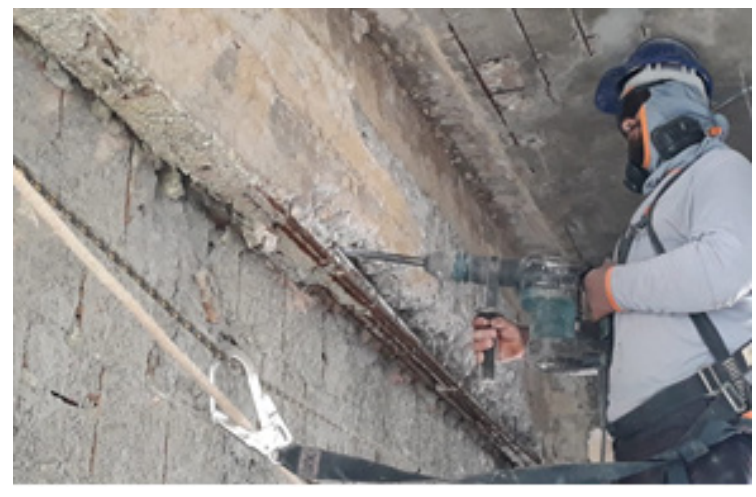

Remoção de concreto nas vigas 
Após a remoção do concreto ao redor das arma duras foram feitas as primeiras avaliações das barras de aço, identificando as que necessitavam de substituição imediata e as que iriam passar pelo procedimento de remoção de ferrugem por abrasão (Figura 6). Após a remoção de toda a ferrugem, foi avaliado o diâmetro final da armadura para verificar, outra vez, a necessidade de substituição das barras (Figura 7a), pois segundo Andrade Perdrix (1992) uma vez que as armaduras estejam completamente limpas e sempre que a redução de seção transversal supere 15 a $25 \%$, é recomendável a colocação de novas armaduras. Terminada esta etapa, foi realizada a limpeza da estrutura retirando partículas soltas com talhadeira manual e marreta, seguida do hidrojateamento, partindo-se então para a etapa de realcalinização.

Figura 6 - Remoção da ferrugem e avaliação da barra

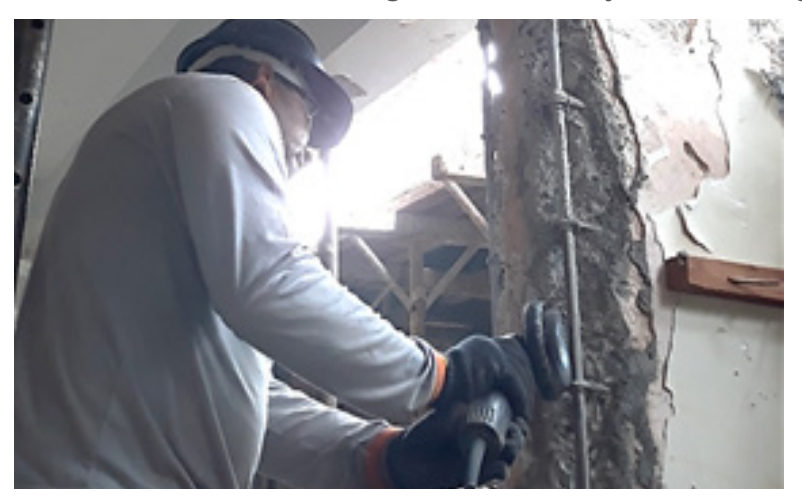

Remoção de ferrugem

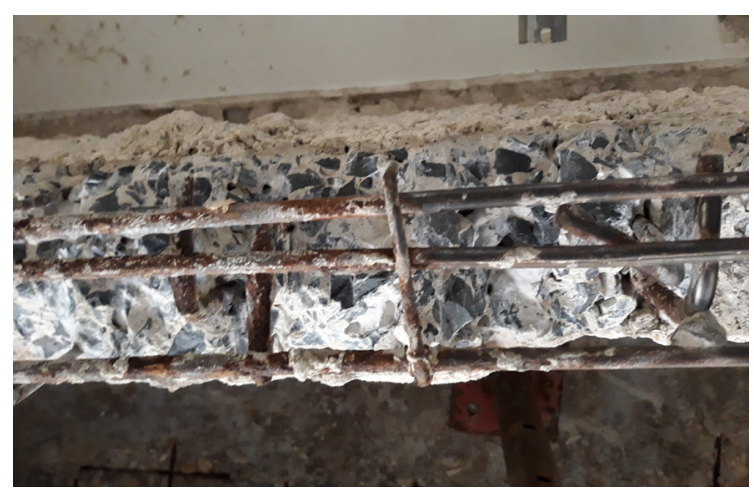

Antes e depois da remoção

Como o concreto não foi removido até sua parte alcalina, foram feitos testes complementares com a solução de fenolftaleína à $1 \%$ para análise de carbonatação, sendo observadas situações onde após a remoção de cerca de 2 centímetros de raio livre da barra o elemento ainda se encontrava carbonatado, onde outras após remoção da camada superficial sofriam reação com a solução, adquirindo uma cor magenta, indicando alcalinidade em sua parte interna (Figura 7b). Como forma complementar de reparo, tomou-se a decisão de aplicar uma realcalinização química em toda a estrutura, pois segundo Andrade Perdrix (1992) a remoção parcial do concreto velho dá origem à uma pilha de corrosão eletroquímica por diferença de material e pH, com a parte antiga atuando como ânodo e a recuperada como cátodo, desencadeando um projeto de corrosão mais rápido que o anterior. 


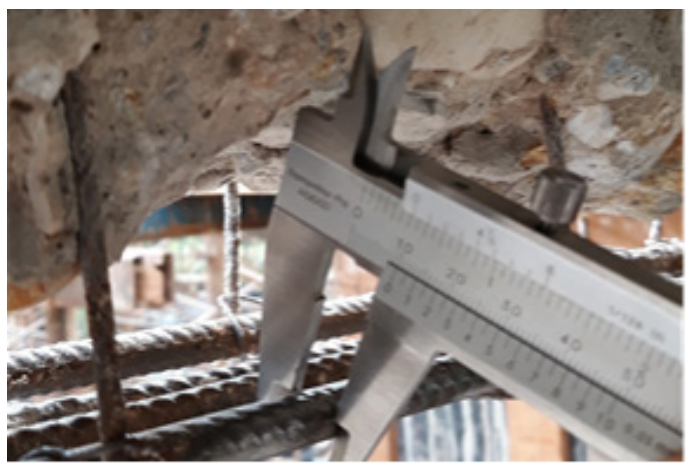

Avaliação da armadura

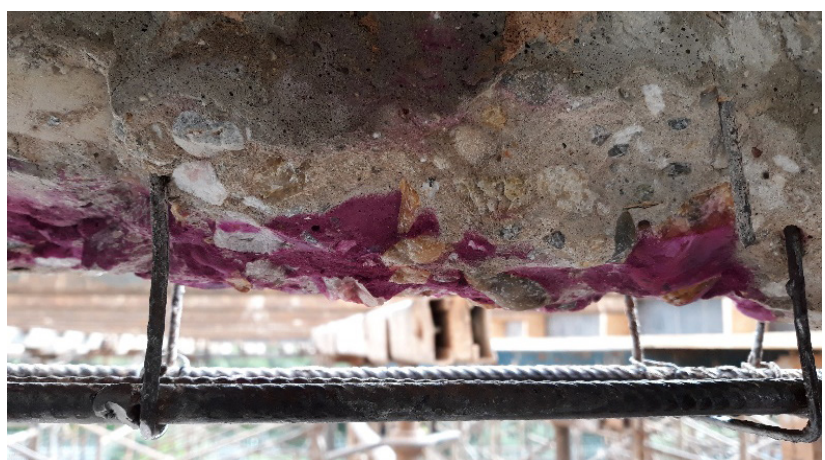

Teste de alcalinidade

Segundo Araújo (2009) na literatura existem três mecanismos para reestabelecer a alcalinidade do meio que rodeia a armadura, o primeiro é através da difusão e absorção de uma solução alcalina por ação capilar e de forças hidráulicas (realcalinização química), o segundo e terceiro ocorrem com o uso de corrente elétrica e consequente formação de um campo elétrico (realcalinização eletroquímica).

A realcalinização escolhida foi a química, com um produto próprio para a absorção e difusão natural no concreto armado. O procedimento foi realizado conforme a orientação do fabricante, sendo aplicadas cinco demãos do produto, aspergidas a cada 30 minutos com pulverizador costal (Figura 8). Por condições de segurança, para a aplicação toda a área ao redor precisou ser isolada até o fim do procedimento.

Figura 8 - Realcalinização química

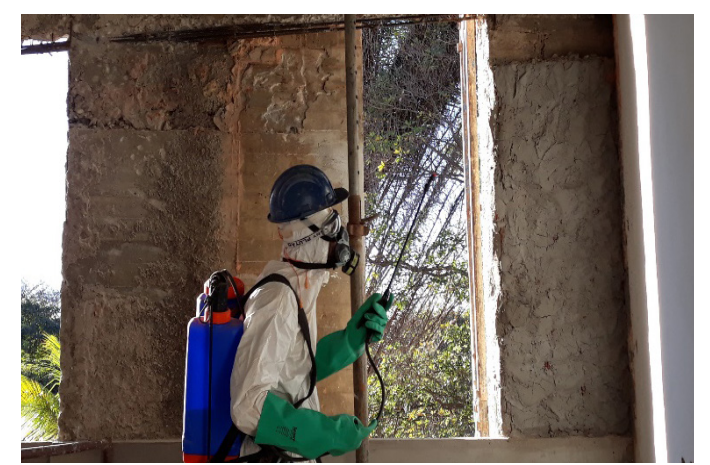

Aplicação do realcalinizante nas vigas

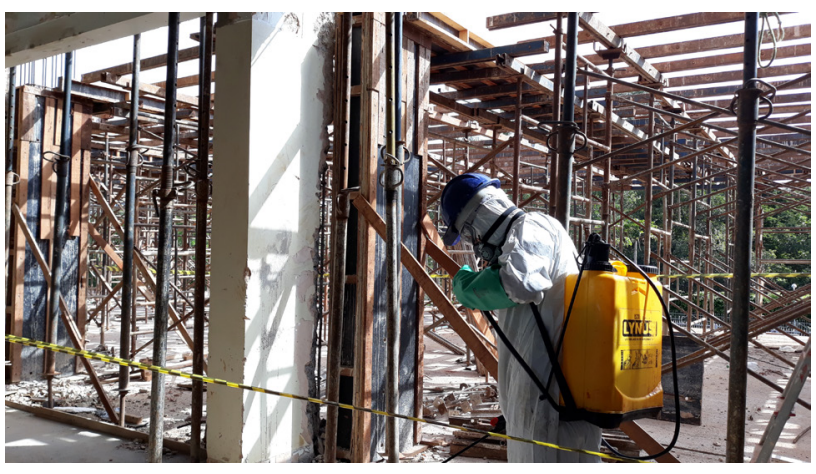

Aplicação do realcalinizante nos pilares

Em sua pesquisa, Araújo (2009) constatou o sucesso da repassivação das armaduras através dos potenciais de corrosão em todas as soluções alcalinas 
estudadas, porém estes os resultados dependem do estágio da propagação da corrosão, sendo provável que tem a realcalinização eletroquímica e a química não proporcione o resultado esperado em um estágio avançado da manifestação patológica. Por isto, tanto para Araújo (2009), quanto para Mietz (1998 apud Ribeiro, 2009), a realcalinização eletroquímica não é apenas um método de reparo e sim um método preventivo, pois atua sobre estruturas em que a profundidade de carbonatação ainda não atingiu o nível das armaduras, prevenindo a corrosão sem intervenções destrutivas, reduzindo-se o custo de possíveis reparos. Porém é necessário observar que a realcalinização, segundo Araújo (2009), não pode ser realizada em concretos que possuem agregados potencialmente reativos, sob o risco de reações álcali-agregado, sendo também a recomendação do Comitê Europeu de Normatização.

Após o preparo do substrato foi executado o preenchimento da área de concreto removida. Nessa etapa faz-se necessário analisar o concreto existente e escolher o melhor material do reparo, considerando compatibilidade entre os mesmos. Existem vários produtos disponíveis no mercado e de acordo com Andrade Perdrix (1992), os mesmos são divididos em três tipos: de base cimentícia, de base polimérica ou resina e os materiais mistos.

Souza \& Ripper (1998) determinam, como itens a serem analisados, que o material de reposição deve ter a resistência maior ou igual ao concreto existente na estrutura, possuir granulometria e diâmetro máximo do agregado compatíveis com o serviço, além de apresentar a trabalhabilidade conveniente para cada tipo de reparo.

Considerando a bibliografia estudada e o fato de que o comprimento de viga a serem reparados totalizaram 260 metros, possuindo vãos com medidas variáveis, optou-se por utilizar em todos os elementos estruturais uma argamassa polimérica cimentícia, monocomponente e tixotrópica, evitando a utilização de fôrmas para cada comprimento reparado.

Examinando as argamassas disponíveis no mercado definiu-se uma argamassa com fibras de vidro integradas, com aditivos auxiliam na inibição de corrosão e na ponte de aderência entre o concreto antigo e o novo, dispensando o uso de adesivos estruturais e a utilização de pinturas especiais. Para a aplicação adicionou-se 3,5 litros de água junto ao conteúdo de 1 saco de argamassa, utilizando misturador mecânico (Figura 9a) de 3 a 5 minutos, obtendo uma mistura homogênea. Decidiu-se utilizar uma fôrma de referência de nível e cobrimento, sendo o preenchimento realizado em duas etapas (Figura 9b). Este fundo fezse necessário devido ao fato de ter sido removido o concreto carbonatado em todo o comprimento das vigas, perdendo-se a referência de nível que o próprio concreto existente fornece, sendo que o uso deste não teve impacto considerável na produtividade por não precisar ter fechamentos exatos e por não necessitar da verificação de estanqueidade. 
Figura 9 - Aplicação da argamassa para o reparo estrutural

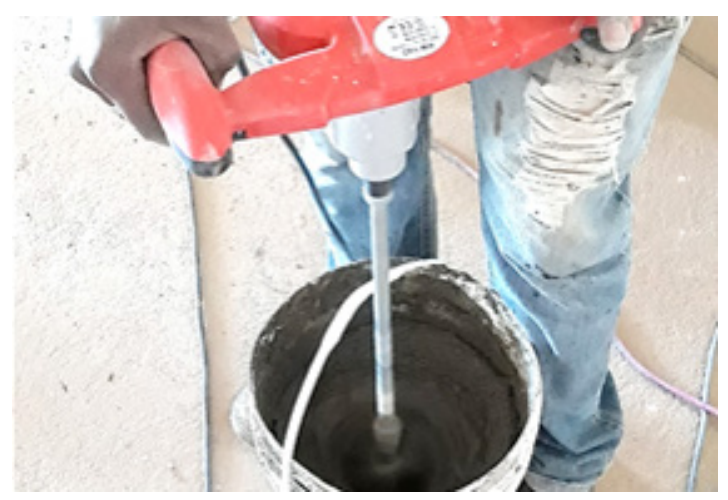

Mistura da argamassa

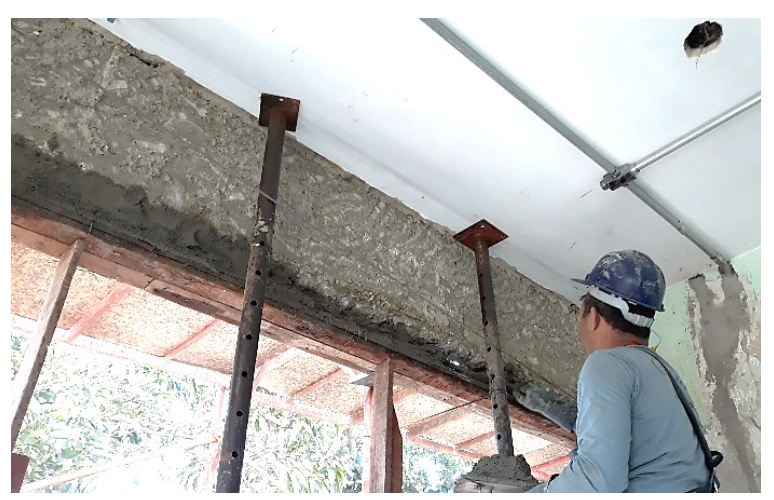

Aplicação do produto

A utilização de material com fibras é mais vantajosa pois segundo Reis (1998) a melhoria no desempenho dos elementos de concreto utilizando fibras submetidos a solicitações tangenciais é registrada por diversos pesquisadores, sendo praticamente consensual a possibilidade de substituir parcialmente os estribos por um volume conveniente de fibras.

Consoante com esta informação, Souza \& Ripper (1998) afirmam que os estribos são a parte da armadura mais expostas e em geral, possuem diâmetros menores, sendo as primeiras a sofrerem corrosão em sua totalidade. Por isto a utilização de fibras faz-se notável, as mesmas auxiliam como armaduras difusas e complementares às barras de aço, melhorando a resistência e o alongamento de ruptura à tração. No presente estudo ainda se pode adicionar ao fato que o agregado graúdo utilizado na edificação antiga é o seixo rolado e neste há uma alta dificuldade de perfuração eficaz para a incorporação de estribos adicionais no elemento estrutural.

Após o preenchimento da seção de concreto anteriormente removida foise realizada a cura úmida e a retirada do escoramento. As escoras foram retiradas de forma parcial para evitar a transmissão imediata de cargas para o elemento reparado.

Para o acabamento final, optou-se por realizar um revestimento com argamassa comum (Figura 10), onde toda a sua superfície foi regularizada e nivelada. O próprio revestimento oferece uma proteção adicional ao concreto reparado. 
Figura 10 - Acabamento após a recuperação

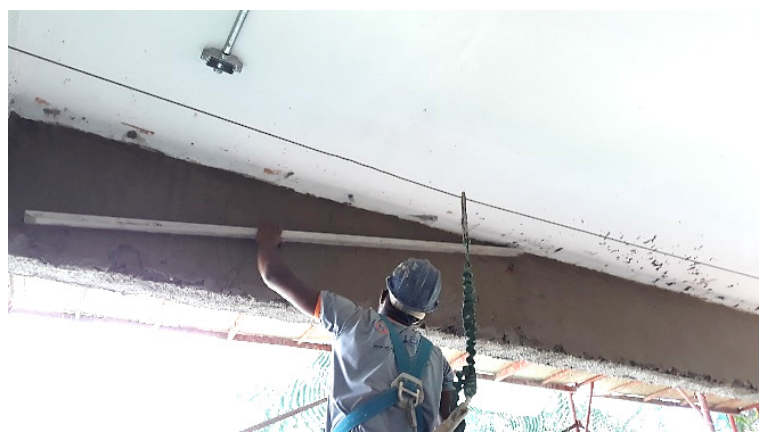

Acabamento final

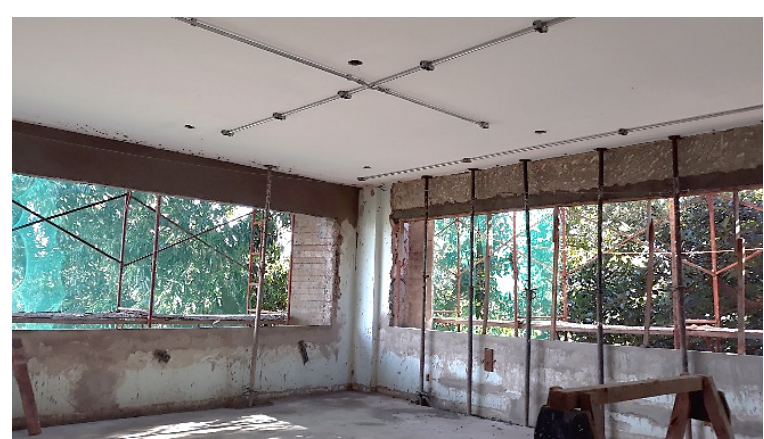

Vigas restauradas

\section{ANÁLISE DOS RESULTADOS}

Ao avaliar a durabilidade é possível afirmar que a capacidade de suporte foi garantida e o bom desempenho da estrutura estendido, contudo, não é possível calcular a vida útil pelo método da velocidade de avanço da frente de carbonatação pois nele é medido o tempo necessário para a cabonatação chegar às armaduras. Neste caso, além das armaduras estarem em processo de corrosão, as mesmas não possuíam cobrimento para a avaliação.

Durante a etapa de reabilitação constatou-se um obstáculo na fiscalização da aplicação do realcalinizante, pois o mesmo é incolor e visualmente não há como constatar a quantidade de demãos. Para aprimorar o monitoramento faz-se necessário um mecanismo que possa trazer praticidade no controle e inspeção da concentração do material aplicado na estrutura.

Já para as argamassas, observou-se que apesar de não precisar de fôrmas, a consistência do material não foi adequada para as vigas, diminuindo a produção pois a mesma tinha uma alta densidade de armaduras (Figura 11). Nota-se que o material utilizado é ideal para pequenos reparos e locais onde há maior dificuldade para aplicação, como por exemplo em reservatórios, porém foi constatado que para este estudo de caso o recomendável seria uma argamassa autonivelante. Para o acabamento final não foram utilizadas telas galvanizadas entre o concreto novo e o concreto antigo. Desta forma, deformação entre a interface poderá ser notada durante as manutenções periódicas, evitando ao máximo mascarar os resultados. Estas, caso ocorram, precisam ser tratadas para garantir a estanqueidade e monitoradas. 
Figura 11 - Alta densidade das vigas

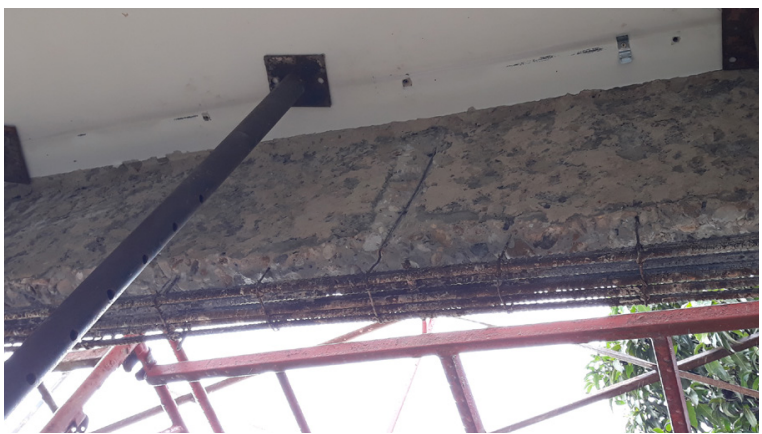

Alta densidade de barras

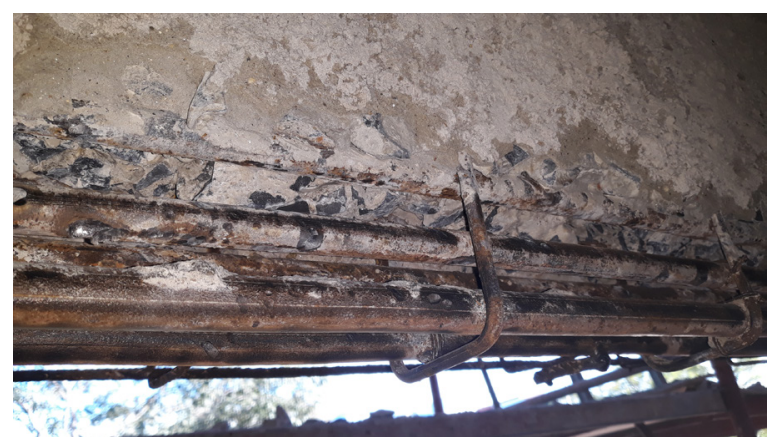

Detalhe após a remoção do concreto

No que refere ao procedimento realizado, o reparo estrutural foi adequado para eliminar todas as manifestações patológicas encontradas e está de acordo com bibliografia estudada. Todavia, faz-se necessário o acompanhamento periódico do comportamento do reparo, pois o mesmo foi realizado apenas nas áreas onde foram identificadas manifestações patológicas, não eximindo o fato de que com o tempo haverá outras áreas críticas, podendo surgir devido à espessura inadequada de cobrimento da armadura.

\section{CONCLUSÕES}

A solução adotada está de acordo com a bibliografia estudada, todos os procedimentos foram fiscalizados e os produtos utilizados conforme as especificações dos fabricantes. Percebe-se que os procedimentos de reparo são únicos para cada problema. Não foi possível padronizar totalmente a solução de reabilitação pois cada elemento estrutural tinha sua singularidade, a quantidade de concreto removido em cada viga não foi a mesma, nem todas as barras de aço necessitaram de serem substituídas, foram encontrados tubos atravessando verticalmente os elementos, barras de aço com posicionamento inadequado e outros. Tendo em vista o caráter artesanal do reparo, notou-se durante o acompanhamento que é primordial a vistoria de um profissional habilitado da área, analisando cada etapa e decidindo quais meios deveriam ser seguidos com base no roteiro pré-determinado. Além disto, por se tratar de um serviço característico, foi necessário o treinamento dos funcionários quanto à aplicação do realcalinizante e aos procedimentos de reparo, junto à conscientização da importância de seguir todas as orientações e informar ao vistoriador quaisquer desconformidades nos elementos estruturais. Durante a execução foram necessários alguns ajustes no preenchimento da seção de concreto, pois a argamassa tixotrópica monocomponente se mostrou eficaz, porém de difícil aplicação no caso de alta densidade de armaduras. $O$ procedimento precisou ser realizado em duas a três etapas para assim garantir que 
o preenchimento fosse adequado, sofrendo impacto no cronograma inicial, com a duração total de três meses.

Durante este estudo de caso foi possível constatar que as manifestações patológicas encontradas poderiam ter sido amenizadas com a utilização do correto cobrimento das armaduras, de forma à servir como barreira física para os agentes patológicos, junto à manutenção preventiva do concreto, com ênfase no aparente, utilizando proteções químicas como a aplicação de materiais hidrofugantes, evitando a variação da umidade nos poros no concreto. Não foi possivel determinar se estes problemas de cobrimento foram devido ao projeto estrutural ou da execução, pois o proprietário não cedeu os arquivos da edificação para o estudo. Percebe-se então que além do estudo de caso, faz-se necessário realizar uma conscientização tanto dos profissionais da área quanto todas as partes envolvidas que a disponibilização de informações da construção e manutenção de uma edificação com manifestações patológicas auxiliam no processo de anamnese, análise estrutural e na escolha do tipo de reabilitação.

O reparo estrutural foi adequado para eliminar todas as manifestações patológicas encontradas, porém se faz necessário acompanhamento periódico da estrutura, analisando seu comportamento ao longo dos anos e avaliando a necessidade de demais intervenções. A princípio, tal acompanhamento poderá ser feito com inspeções visuais e controle de potencial de corrosão, podendo assim analisar a velocidade da deterioração da estrutura, tendo em vista que os elementos estruturais que não possuíam manifestações patológicas, não sofreram intervenções.

Este estudo de caso serviu para contribuir com informações a respeito da execução e diagnóstico de manifestações patológicas. Na área de patologia há poucos trabalhos que unem diagnóstico com o procedimento de execução in loco e são ainda mais raros aqueles que acompanham a estrutura reparada e a eficácia das soluções empregadas. Percebe-se a necessidade de atenção a este ramo da engenharia, pois a tendência é que a solicitação seja cada vez maior, tendo em vista o processo natural da degradação das estruturas. Ainda, é preciso conciliar o trabalho de laboratório com o de campo, aumentando as ferramentas de análises não destrutivas que podem ser realizadas no local, tanto no diagnóstico quanto na execução e manutenção dos elementos reabilitados, criando assim uma variedade de informações sobre cada solução adotada e seu impacto na vida útil da estrutura.

\section{REFERÊNCIAS}

Andrade Perdrix, M. d. Manual para diagnóstico de obras deterioradas por corrosão de armaduras. São Paulo, Brasil: Pini, p. 104, 1992. 
Araújo, F. W. Estudo da repassivação da armadura em concretos carbonatados através da técnica de realcalinização química. Tese de doutorado, Universidade de São Paulo, p. 217, 2009.

Baver, L. A. Materiais de Construção Vol 1. Rio de Janeiro: LTC - Livros Técnicos e Científicos Editora LTDA, p. 488, 2008.

Helene, P. R. Contribuição ao estudo da corrosão em armaduras de concreto armado. Tese de doutorado, Universidade de São Paulo, p. 231, 1993.

Molin, D. C. Fissuras em estruturas de concreto armado. Dissertação de mestrado, Universidade Federal do Rio Grande do Sul, p. 220, 1988.

Reis, A.P. Reforço de vigas de concreto armado por meio de barras de aço adicionais ou chapas de aço e argamassa de alto desempenho. Dissertação de mestrado, Universidade de São Paulo, p. 179, 1998.

Ribeiro, J. L. Contribuição para a avaliação da compatibilidade eletroquímica entre argamassas de reparo e concreto carbonatado. Tese de doutorado, Universidade de São Paulo, p. 122, 2009.

Ribeiro, P. H. Realcalinização eletroquímica de estruturas de concreto armado carbonatadas inseridas no meio urbano - influência de características da estrutura no comportamento do tratamento. Dissertação de mestrado, Universidade Federal da Paraíba, p. 143, 2009.

Souza, V. C., Ripper, T. Patologia, Recuperação e Reforço de Estruturas de Concreto. São Paulo: Pini, p. 257, 1998. 